\title{
Glucose and Electrolytes Concentrations in Blood and Saliva Samples amongst Diabetics
}

\section{Mieebi Martin Wankasi ${ }^{*}$, Eni-yimini Solomon Agoro², Charles German Ikimi³, Edidiong Okon Tommy ${ }^{4}$}

\author{
${ }^{1}$ The Department of Medical Laboratory Science, College of Health Science, Niger Delta University, \\ Wilberforce Island, Nigeria \\ ${ }^{2}$ Enis Biomedicals and Forensics (EBF) LTD., Yenagoa, Nigeria \\ ${ }^{3}$ Department of Biochemistry, Federal University Otuoke, Otuoke, Nigeria \\ ${ }^{4}$ Department of Haematology and Blood Transfusion, Federal Medical Centre, Yenagoa, Nigeria \\ Email: *mieebiwankasi@gmail.com
}

How to cite this paper: Wankasi, M.M. Agoro, E.S., Ikimi, C.G. and Tommy, E.O. (2019) Glucose and Electrolytes Concentrations in Blood and Saliva Samples amongst Diabetics. Journal of Diabetes Mellitus, 9 , 39-49.

https://doi.org/10.4236/jdm.2019.92005

Received: January 28, 2019

Accepted: May 19, 2019

Published: May 22, 2019

Copyright $\odot 2019$ by author(s) and Scientific Research Publishing Inc. This work is licensed under the Creative Commons Attribution International License (CC BY 4.0).

http://creativecommons.org/licenses/by/4.0/

cC) (7) Open Access

\begin{abstract}
Diabetes mellitus is a group of metabolic disorders of carbohydrate metabolism in which glucose is underutilized, producing hyperglycaemia. The management requires proper maintenance of glucose and electrolytes within its optimum concentrations. The study was designed to evaluate the possibility of using saliva as an alternative non-invasive sample for the determination of electrolytes. A total of 100 samples were utilized consisting of equal number of control (non-diabetics) and diabetic groups. Fasting blood and saliva were collected employing standard methods. The biochemical parameters were analysed using WHO approved methods and procedures. Independent samples t-test and Pearson correlation were the statistical tools used for the data analysis obtained from SPSS package (version 20). The study revealed a significant increase $(\mathrm{p}<0.05)$ in concentrations of blood and salivary glucose, potassium and calcium when controls were compared to diabetics. Moreover, there was a high level of semblances and patterns between plasma and salivary electrolytes, except for potassium. Therefore, electrolytes and glucose results gotten from the use of saliva could be used to equate to that of blood. Hence, instances of non-accessibility of blood, saliva could be of help.
\end{abstract}

\section{Keywords}

Saliva, Blood, Electrolytes, Glucose, Non-Invasive

\section{Introduction}

Diabetes mellitus is a group of metabolic disorders of carbohydrate metabolism 
in which glucose is underutilized, producing hyperglycaemia [1]. It is a floodgate to kidney failure, cardiac dysfunction, and arrays of other diseases [2]. Fasting blood glucose will usually be less than $6.0 \mathrm{mmol} / \mathrm{l}$ in a non-diabetic patient. Results of $6-8 \mathrm{mmol} / \mathrm{l}$ are border line, but a result of greater than $8 \mathrm{mmol} / \mathrm{l}$ on two occasions is diagnostic for diabetes mellitus [3].

The increasing prevalence of diabetes worldwide has led to a situation where approximately 360 million people had diabetes in 2011. This number is estimated to increase to 552 million by 2030 [4]. The diagnosis and management of diabetes mellitus involves pricking, which is an invasive method and could be painful, characterized by hazard of getting infections, complications in haemophilic patients and various other disadvantages [5]. The invasiveness is one of the major obstacles to the control of diabetes mellitus as many alleged sufferers usually abstain from the procedure. This has brought about the quest for an alternative that is non-invasive and that could be a substitute to blood. Studies have shown the usefulness of saliva in the determination of glucose and other parameters of use in the management of diabetes mellitus [6]-[11].

The proper management of diabetes mellitus involved the use of arrays of biochemical parameters of which electrolytes rank among the top. This is due to the vital roles electrolytes play in metabolism and physiology. Electrolytes are certain minerals that in solution break apart and become electrolyzed [12]. These electrolytes are capable of conducting an electrical current [13]. The primary electrolytes found in plasma are sodium, chloride, bicarbonates, calcium and potassium. Within the body, electrolytes are found in both the intracellular and extracellular fluid.

Saliva is an exocrine secretion of the salivary glands, containing water (99\%), electrolytes, proteins, and enzyme. It provides sensory perception of food, and aids chewing, swallowing, and digestion of food [14]. Hundreds of components found in saliva may serve to detect systemic diseases or as evidence of exposure to various harmful substances, as well as provide biomarkers of health and disease status. Nowadays, the saliva research is rapidly advancing due to the use of novel approaches including metabolomics, genomics, proteomics and bioinformatics [15].

There is increased interest towards non-invasive method to diagnose this disease, one of which is saliva [16]. The analyses of electrolytes are blood dependent which is an invasive method. The saliva matrix is an upcoming area of research for basic and clinical application purposes, with considerable potential for growth and progress. Hence, the focus of this study is the possibility of utilizing saliva as a substitute for the determination of electrolytes in diabetics and to assess the relationship between plasma and salivary electrolytes.

\section{Methodology}

\subsection{Study Area}

This study was carried out in Bayelsa state of Nigeria. Samples were collected from the Federal Medical Centre (FMC) Yenagoa, Bayelsa state between the 
months of January to July 2018. Bayelsa state is located within Latitude $40151^{\circ}$ North and Latitude $50^{\circ}$ and $231^{\circ}$ South. It is also within longitude $50221^{\circ}$ West and $60451^{\circ}$ East. It is bounded by Delta State on the North, Rivers State on the East and the Atlantic Ocean on the Western and Southern parts. According to the 2006 census figures, Bayelsa has a population of about 1.7 million people.

\subsection{Ethical Clearance}

Approval for the study was obtained from the ethics committee of the Federal Medical Centre Yenagoa, Bayelsa state. Also, verbal informed consent was obtained from each subject before sample collection.

\subsection{Study Population}

A total of one hundred (100) subjects were utilized for the study as validated by G-power software. Fifty (50) each constituted the experimental and the control groups respectively. The experimental group was made up of subjects with history of diabetes mellitus (type I \& II) with fasting blood glucose concentration more than $6.0 \mathrm{mmol} / \mathrm{L}$. The controls subject's fasting blood glucose concentrations were less than $5.0 \mathrm{mmol} /$ and without diabetes mellitus histories. The gender was also balanced with age brackets between 26 and 72 years.

\subsection{Exclusion and Inclusion Criteria}

Subjects with diabetes mellitus and those without diabetes mellitus were recruited for the study. The status of diabetes mellitus was determined as per the criteria by The Expert Committee on Diagnosis and classification of Diabetes mellitus, 1998. Patients with severe diabetic complications were excluded. Study participants with any other systemic illness or on medications other than for diabetes were also excluded.

\subsection{Collection of Samples}

Blood

Standard for phlebotomy was stringently adhered. Six (6) $\mathrm{ml}$ of fasting blood was collected, $4 \mathrm{ml}$ dispensed into plain container and $2 \mathrm{ml}$ into fluoride oxalate container. The samples in the plain containers were used for the estimation of electrolytes, whereas that of fluoride oxalate for glucose estimation. Standard procedure for blood collection and separation was strictly followed.

Saliva

Salivary sample collection was done in the morning between 8.00-10.00a.m using unstimulated spitting method. Study subjects were instructed not to smoke or brush or eat or drink eight hours prior to the time of saliva collection. In the beginning, subjects were asked to spit out initial saliva within the first thirty seconds before main collection commenced. Salivary samples were collected into the containers as was done using blood. The samples were spun and the supernatant used for the analysis. 


\subsection{Laboratory Methods}

Blood and salivary glucose were estimated using glucose oxidase method, whereas the electrolytes utilized ion selective electrolyte (ISE) method. Both methods are WHO approved methods as stated by Ashwood et al. [1].

\subsection{Statistical Analysis}

Concentrations of analytes were expressed as mean \pm standard deviation. The data obtained were analyzed using independent samples student $t$-test using SPSS statistical package (version 20). The level of significance was pegged at $\mathrm{p}<$ 0.05 . Pearson correlation was used to determine the association between the various biochemical parameters in plasma and saliva.

\section{Results}

Table 1 shows that of all the biochemical parameters studied, only potassium concentration was higher in saliva as compared to blood, while others were lower in concentration.

Table 2 shows that all the parameters mentioned above showed significant increase ( $\mathrm{p}<0.05)$ when compared between blood and saliva.

Table 3 show a significant increase in the concentrations of glucose, potassium, total calcium, ionized calcium and non-ionized calcium in diabetics when compared with non-diabetics.

Table 4 shows a significant increase in the saliva concentrations of glucose, potassium, total calcium, and ionized calcium in diabetics when compared with non-diabetics.

Table 5 shows no significant correlation existence between studied biochemical parameters in saliva and blood of non-diabetic subjects.

Table 6 shows no significant correlation existence between studied biochemical parameters in saliva and blood of diabetic subjects.

Table 1. Comparison of the concentrations of blood and saliva glucose for the parameters estimated for control (non-diabetics).

\begin{tabular}{cccc}
\hline PARAMETERS & BLOOD & SALIVA & p-VALUE \\
\hline Glucose $\mathrm{mmol} / \mathrm{l}$ & $4.69 \pm 0.53$ & $0.10 \pm 0.70$ & $\mathrm{p}<0.05$ \\
Potassium $\mu \mathrm{mol} / \mathrm{l}$ & $3.68 \pm 0.10$ & $16.56 \pm 3.27$ & $\mathrm{p}<0.05$ \\
Sodium $\mu \mathrm{mol} / \mathrm{l}$ & $140.30 \pm 1.04$ & $12.24 \pm 1.84$ & $\mathrm{p}<0.05$ \\
Chloride $\mu \mathrm{mol} / 1$ & $104.09 \pm 1.28$ & $19.39 \pm 4.81$ & $\mathrm{p}<0.05$ \\
$\mathrm{pH}$ & $7.71 \pm 0.17$ & $6.71 \pm 0.44$ & $\mathrm{p}<0.05$ \\
Ionized Ca $\mu \mathrm{mol} / \mathrm{l}$ & $1.01 \pm 0.06$ & $0.67 \pm 0.14$ & $\mathrm{p}<0.05$ \\
Calcium $\mu \mathrm{mol} / 1$ & $1.16 \pm 0.07$ & $0.40 \pm 0.11$ & $\mathrm{p}<0.05$ \\
$\mathrm{nCa} \mu \mathrm{mol} / \mathrm{l}$ & $2.30 \pm 0.15$ & $0.72 \pm 0.24$ & $\mathrm{p}<0.05$ \\
Total Calcium $\mu \mathrm{mol} / 1$ & & & \\
\hline
\end{tabular}

Legend: $\mathrm{p}<0.05$ is significant, whereas $\mathrm{p}>0.05$ is not significant, $\mathrm{nCa}=$ Non-ionized calcium. 
Table 2. Comparison of concentrations of blood and saliva for the parameters estimated for diabetics.

\begin{tabular}{cccl}
\hline PARAMETERS & BLOOD & SALIVA & p-VALUE \\
\hline & $($ Mean \pm SD $)$ & $($ Mean \pm SD $)$ & \\
Glucose & $10.57 \pm 0.65$ & $0.81 \pm 0.29$ & $\mathrm{p}<0.05$ \\
Potassium & $4.11 \pm 0.37$ & $24.55 \pm 4.33$ & $\mathrm{p}<0.05$ \\
Sodium & $137.66 \pm 1.71$ & $8.76 \pm 2.76$ & $\mathrm{p}<0.05$ \\
Chloride & $98.65 \pm 3.70$ & $16.36 \pm 7.83$ & $\mathrm{p}<0.05$ \\
pH & $7.77 \pm 0.11$ & $6.52 \pm 0.34$ & $\mathrm{p}<0.05$ \\
Ionized calcium & $1.22 \pm 0.63$ & $0.89 \pm 0.32$ & $\mathrm{p}<0.05$ \\
nCa & $1.49 \pm 0.69$ & $0.46 \pm 0.07$ & $\mathrm{p}<0.05$ \\
Total Calcium & $2.89 \pm 1.37$ & $1.87 \pm 1.10$ & $\mathrm{p}<0.05$ \\
\hline
\end{tabular}

Legend: $\mathrm{p}<0.05$ is significant, whereas $\mathrm{p}>0.05$ is not significant, $\mathrm{nCa}=$ Non-ionized calcium.

Table 3. Comparison of concentration of blood glucose and electrolytes in non-diabetics and diabetics.

\begin{tabular}{cccc}
\hline PARAMETERS & NON-DIABETICS & DIABETICS & p-VALUE \\
\hline & $($ Mean \pm SD $)$ & $($ Mean \pm SD $)$ & \\
Glucose & $4.69 \pm 0.53$ & $10.57 \pm 0.65$ & $\mathrm{p}<0.05$ \\
Potassium & $3.68 \pm 0.10$ & $4.11 \pm 0.37$ & $\mathrm{p}<0.05$ \\
Sodium & $140.30 \pm 1.04$ & $137.66 \pm 1.71$ & $\mathrm{p}>0.05$ \\
Chloride & $104.09 \pm 1.28$ & $98.65 \pm 3.70$ & $\mathrm{p}>0.05$ \\
$\mathrm{pH}$ & $7.71 \pm 0.17$ & $7.77 \pm 0.11$ & $\mathrm{p}>0.05$ \\
Total Calcium & $2.30 \pm 0.15$ & $2.89 \pm 1.37$ & $\mathrm{p}<0.05$ \\
nCa & $1.16 \pm 0.07$ & $1.49 \pm 0.69$ & $\mathrm{p}<0.05$ \\
Ionized calcium & $1.01 \pm 0.06$ & $1.22 \pm 0.63$ & $\mathrm{p}<0.05$ \\
\hline
\end{tabular}

Legend: $\mathrm{nCa}=$ Non-ionized Calcium.

Table 4. Comparison of concentrations of saliva glucose and electrolytes in non-diabetics and diabetics.

\begin{tabular}{cccc}
\hline PARAMETERS & CONTROL & DIABETICS & p-VALUE \\
\hline Glucose & (Mean \pm SD) & $($ Mean \pm SD $)$ & $\mathrm{p}<0.05$ \\
Potassium & $0.10 \pm 0.70$ & $0.81 \pm 0.29$ & $\mathrm{p}<0.05$ \\
Sodium & $16.56 \pm 3.27$ & $24.55 \pm 4.33$ & $\mathrm{p}<0.05$ \\
Chloride & $11.78 \pm 1.52$ & $8.76 \pm 2.76$ & $\mathrm{p}>0.05$ \\
pH & $19.39 \pm 4.81$ & $16.36 \pm 7.83$ & $\mathrm{P}>0.05$ \\
Total Calcium & $6.71 \pm 0.44$ & $6.52 \pm 0.34$ & $\mathrm{p}<0.05$ \\
nCa & $0.72 \pm 0.24$ & $1.87 \pm 1.42$ & $\mathrm{p}>0.05$ \\
Ionized calcium & $0.40 \pm 0.11$ & $0.46 \pm 0.07$ & $\mathrm{p}<0.05$ \\
\hline
\end{tabular}

Legend: $\mathrm{nCa}=$ Non-ionized Calcium. 
Table 5. Observed Pearson's correlation between blood and salivary studied biochemical parameters in non-diabetic (control).

\begin{tabular}{ccc}
\hline PARAMETERS & $\mathrm{r}$ & $\mathrm{p}$-VALUE \\
\hline Glucose & 0.349 & $\mathrm{p}>0.05$ \\
Potassium & -0.200 & $\mathrm{p}>0.05$ \\
Sodium & 0.459 & $\mathrm{p}>0.05$ \\
Chloride & 0.294 & $\mathrm{p}>0.05$ \\
$\mathrm{pH}$ & 0.603 & $\mathrm{p}>0.05$ \\
Ionized calcium & 0.188 & $\mathrm{p}>0.05$ \\
Non-Ionized calcium & -0.019 & $\mathrm{p}>0.05$ \\
Total Calcium & 0.132 & $\mathrm{p}>0.05$ \\
\hline
\end{tabular}

Table 6. Observed Pearson's correlation between blood and salivary studied biochemical parameters in diabetics.

\begin{tabular}{ccc}
\hline PARAMETERS & $\mathrm{r}$ & $\mathrm{p}$-value \\
\hline Glucose & 0.053 & $\mathrm{p}>0.05$ \\
Potassium & 0.304 & $\mathrm{p}>0.05$ \\
Sodium & 0.092 & $\mathrm{p}>0.05$ \\
Chloride & -0.440 & $\mathrm{p}>0.05$ \\
$\mathrm{pH}$ & -0.401 & $\mathrm{p}>0.05$ \\
Ionized calcium & -0.232 & $\mathrm{p}>0.05$ \\
nCa & 0.273 & $\mathrm{p}>0.05$ \\
Total Calcium & -0.090 & $\mathrm{p}>0.05$ \\
\hline
\end{tabular}

\section{Discussion}

The results obtained from this study showed that the mean concentrations of glucose, chloride, $\mathrm{pH}$, ionized calcium, non-ionized calcium and total calcium were higher in the blood than in the saliva, whereas potassium was higher in the saliva than in the blood (see Table $1 \&$ Table 2). These findings were observed both in non-diabetics (control) and diabetics groups. The semblances of the findings both in the control and experimental groups have further posited the shared-similarity in the pattern of molecule migration between the blood and saliva. The findings of this study is consistent with previous report by John et al. [17], who stated that the concentration of both sodium and chloride are several times less in saliva than in the plasma but the contrary was reported for potassium and bicarbonate. Our findings concurred with previous report by Agoro et al. [10] [11] that showed a geometric increase in concentration of glucose in blood as compared to saliva. The higher concentration observed in the blood for the above stated biochemical parameters could be due to the large volume and surface area of blood. Also, blood is an extracellular fluid from where a lot of nutrients and electrolytes are gotten rid from the body or transported to other 
cells, tissues and body fluids for systemic sustenance. In contrast, potassium was seen to be higher in saliva. This could be attributed to the filtration of potassium into the saliva and the active release to the saliva by nerves stimulation as reported by Carlos et al. [18]. Also sodium ions are actively reabsorbed from all the salivary ducts and potassium ions are actively secreted in exchange for the sodium. Therefore, the sodium ion concentration of the saliva becomes greatly reduced, whereas the potassium ion concentration becomes increased. These factors contributed to the higher concentration of potassium concentration in the saliva when compared to the blood.

However, the results obtained from the comparison between the studied blood biochemical parameters of non-diabetics and diabetics exhibited a significant increased $(\mathrm{p}<0.05)$ in the concentration of blood glucose, potassium, ionized calcium, non-ionized and total calcium in diabetics (Table 3). Almost similar increase was seen in the saliva in diabetics except for non-ionized calcium that was not significant in the saliva (Table 4) between non-diabetics and diabetics.

The increase as observed in blood glucose amongst diabetics is an established fact. The increase in salivary glucose concentration amongst diabetes mellitus as indicated in this study agreed with that Agoro et al. [10] [11], Chavez et al. [6], Pal et al. [7], Lopez et al. [8] and Amer et al. [9]. This observation further advocated the need for the use of salivary glucose in the diagnosis of diabetes especially when the access to blood is hampered. The high level of glucose in the saliva of diabetics probably reflects the high blood concentrations, and this may be due to diabetes membranopathy which may lead to raised percolation of glucose from blood to saliva and alter salivary composition in diabetes mellitus [9]. Furthermore, the increase in salivary glucose could be attributed to a spill-over effect from the blood and microvascular leakage [10]. The increase in salivary glucose may be the result of excess glucose in the blood, hence a diffusion mechanism that resulted in the movement of glucose to other fluids in the body inclusive of the saliva.

Calcium concentrations were low in the saliva as previously reported by Shirzaiy et al. [19] and we also revealed in this study substantially lower calcium in saliva compared to plasma. The significant increase in serum and salivary calcium as observed in the study is in consonance with previous report by Nerea et al. [20]. The increase in calcium concentration is mostly associated with cardiovascular diseases. Diabetes mellitus is one of the culprits of cardiovascular disease. Hence the increase as observed in this study could be an indicator of potentiality of cardiovascular disease. An increase in serum calcium concentrations is associated with type 2 diabetes and individuals at higher cardiovascular risk [20].

Moreover, the study observed an increase in the concentration of potassium both in the blood and saliva of diabetics when compared with the controls. This result is in accordance with a previous study by Sharon et al. [21]. A study by Antonios and Pratap, [22] noted same findings in term of the increase in serum 
potassium amongst diabetes. The reasons for the increase in concentration as observed for serum and salivary potassium could be multifaceted. Diabetes mellitus could lead to a lot of complications, such as kidney and cardiac diseases. These complications are known to cause hyperkalemia. Increase in potassium is mostly an indicator of cardiovascular damage. The increase in serum potassium has further shown the vulnerability of diabetics to renal or/and cardiac diseases. Sodium ions are known to be actively reabsorbed from all the salivary ducts and potassium ions are actively secreted in exchange for the sodium. These could further contribute to the elevation of potassium both in the blood and saliva. Sharon et al. [21], Ben-Aryeh et al. [23] and Yavuzyilmaz et al. [24] analyzed whole saliva, and found significantly higher potassium levels in diabetic groups compared to the nondiabetic group. Sharon et al. [21] citing studies in animals have hypothesized that in diabetes mellitus an autonomic neuropathy exists that causes sympathetic-parasympathetic imbalance. This imbalance may perhaps exert a continuous stimulation on the salivary glands, bringing about increased potassium secretion into the saliva. In the contrary, Mander et al. [25] and Streckfus et al. [26] analyzed individual gland saliva and they found no significant difference controls and diabetics. Marder et al. [25] attempted to explain the higher concentration of potassium in whole saliva of diabetics by different factors such as peripheral vascular damage that had much higher potassium levels in diabetics than controls and elevated conductibility of the acinic cell membrane to potassium [27].

The results obtained from this study also demonstrated that there was no significant correlation between fasting blood glucose, potassium, sodium, ionized calcium, $\mathrm{pH}$, chloride, non-ionized calcium and total calcium in both control group (non-diabetics) and diabetic group (Table 5 \& Table 6). The blood and salivary glucose non correlation as observed in this study agreed with the view of Agoro et al., [11]. Agoro et al. [10] stated that salivary and blood glucose could only correlate when the glucose concentrations are above threshold values. On the other hand, the findings disagreed with Prakash et al. [28] who reported a positive significant correlation between fasting salivary glucose and fasting serum glucose in diabetics and non-diabetics.

\section{Limitation of Study}

The major hindrance to the study was paucity of funds and difficulty in accessing willing subjects. Coupled to that was non-available of most recent robotic chemistry analyser which give better precision and accuracy of results especially in measuring salivary biochemical parameters which are predominantly very low.

\section{Conclusion}

This study has shown that the studied biochemical parameters obtained in the blood and saliva of non-diabetics and diabetics are similar though not corre- 
lated. Hence, situations of difficulty in accessing blood, saliva could be of help especially in management requiring electrolytes analysis. However, we support that blood is still the best choice for the diagnosis and management of diabetes mellitus.

\section{Conflicts of Interest}

The authors declare no conflicts of interest regarding the publication of this paper.

\section{References}

[1] Ashwood, E.R., Bruns, D.E. and Burtis, A.C. (2012) Carbohydrates. In: Tietz Fundamentals of Clinical Chemistry, 7th Edition, Elsevier, New Delhi, 373-395.

[2] Agoro, E.S., Wankasi, M.M. and Illeimokum, O. (2015) Relationship between Serum Anion Gap and Diabetes Mellitus. Journal of Diabetes Mellitus, 5, 199-205. https://doi.org/10.4236/jdm.2015.54024

[3] Baker, F.J., Silverton, R.E. and Pallister, C.J. (2001) Gastric and Pancreatic Function Tests. In: Introduction to Medical Laboratory Technology, 7th Edition, Edward Arnold, London, 103-129.

[4] Knip, M., Virtanen, S.M. and Akerblom, H.K. (2010) Guidelines on Diabetes, Prediabetes, and Cardiovascular Diseases Developed in Collaboration. European Heart Journal, 91, 1506-1513.

[5] Mitsumari, M., Yamaguchi, M. and Kano, Y.A. (1998) A New Approach to Non-Invasive Measurement of Blood Glucose Using Saliva Analyzing System. England Medicine and Biological Society, 4, 1767-1770.

[6] Chávez, E.M., Borell, L.N., Taylor, G.W. and Ship, J.A. (2001) A Longitudinal Analysis of Salivary Flow in Control Subjects and Old Adults with Type 2 Diabetes. Oral Surgery, Oral Medicine, Oral Pathology, Oral Radiology, and Endodontics, 91, 166-173. https://doi.org/10.1067/moe.2001.112054

[7] Pal, P., Desai, N.T., Kannan, N., Masur, V.N., Daniel, M.J. and Bhatt, N. (2003) Estimation of Salivary Glucose, Salivary Amylase, Salivary Total Protein and Periodontal Microflora in Diabetes Mellitus. Journal of the Indian Dental Association, 74, 143-149.

[8] Lopez, M.E., Colloca, M.E., Paez, R.G., Schallmach, J.N., Koss, M.A. and Chervonagura, A. (2003) Salivary Characteristics of Diabetic Children. Brazilian Dental Journal, 14, 26-31. https://doi.org/10.1590/S0103-64402003000100005

[9] Amer, S., Yousuf, M., Siddiqiui, P.Q. and Alam, J. (2001) Salivary Concentrations in Patients with Diabetes Mellitus-A Minimally Invasive Technique for Monitoring Blood Glucose Levels. Pakistan Journal of Pharmaceutical Science, 14, 33-37.

[10] Agoro, E.S., Nelson-Ebimie, E., Soroh, A.E. and Odegbemi, J.O. (2017) The Suitability of Non-Invasive Sample in the Assay of Glucose in Diabetes Mellitus Diagnosis and Sex Difference. Journal of Applied Microbiology and Biochemistry, 2, 6.

[11] Agoro, E.S., Ebiere, N.E., Eseimokumo, S.A. and Odegbemi, J.O. (2017) Is Saliva an Alternative Non-Invasive Sample for the Estimation of Protein Profile amongst Diabetics and Gender-Based Diagnostics? Anatomy and Physiology: Current Research, 7, 255.

[12] Nielsen, M. (1995) Ions: The Body's Electrical Energy Source. Mineral Resources International, 9, 178-183. 
[13] Horne, M.M. and Swearingen, P.L. (1989) Fluids, Electrolytes, and Acid-Base Balance. In: Year Book, $2^{\text {nd }}$ Edition, Mosby, Saint Louis, 64-69.

[14] De Almeida, P.V., Gregio, A.M., Machado, M.A., De Lima, A.A. and Azevedo, L.R. (2008) Saliva Composition and Functions: A Comprehensive Review. Journal Contemporary Dental Practice, 9, 72-80.

[15] Ahmadi, M.F., Davoodi, P. and Dalband, M. (2010) Saliva as a Mirror of the Body Health. DJH, 1, 1-15.

[16] Sreedevi, S.M.C. and Shambulingappa, P. (2008) Comparison of Serum Glucose and Salivary Glucose in Diabetic Patients. Journal of Indian Academy of Oral Medicine and Radiology, 20, 9-13. https://doi.org/10.4103/0972-1363.44354

[17] John, O.O. and Arundhati, A.K. (2007) Carbohydrate Metabolism. In: Medical Laboratory Science Theory and Practice, $6^{\text {th }}$ Edition, Tata McGraw-Hill, New Delhi, 99-110.

[18] Carlos, L., Silke, T., John, P., Mohamed, T., Simon, N.T., Athanase, B. and Magnus, B. (2018) Differential Associations for Salivary Sodium, Potassium, Calcium, and Phosphate Levels with Carotid Intima Media Thickness, Heart Rate, and Arterial Stiffness. Disease Markers, 2018, Article ID: 3152146. https://doi.org/10.1155/2018/3152146

[19] Shirzaiy, M., Heidari, F., Dalirsani, Z. and Dehghan, J. (2015) Estimation of Salivary Sodium, Potassium, Calcium, Phosphorus and Urea in Type II Diabetic Patients. Diabetes and Metabolic Syndrome: Clinical Research and Reviews, 9, 332-336. https://doi.org/10.1016/j.dsx.2013.02.025

[20] Nerea, B.T., Ramón, E., Mònica, B., Rosa, C., Andrés, D.L., Josep, B., Montserrat, F., Lluis, S.M. and Jordi, S.S. (2014) Increased Serum Calcium Levels and Risk of Type 2 Diabetes in Individuals at High Cardiovascular Risk. Diabetes Care, 37, 3084-3091. https://doi.org/10.2337/dc14-0898

[21] Sharon, A., Hannah, B.A., Biran, I., Yoram, K., Szargel, R., Gutman, D., et al. (1985) Salivary Composition in Diabetic Patients. Journal of Oral Medicine, 40, 23-26.

[22] Antonios, H.T. and Pratap, S.A. (1987) Serum Potassium Concentration in Hyperglycemia of Diabetes Mellitus with Long-Term Dialysis. Western Journal of Medicine, 146, 571-575.

[23] Ben-Aryeh, H., Serouya, R., Kanter, Y., Szargel, R. and Laufer, D. (1993) Oral Health and Salivary Composition in Diabetic Patients. Journal of Diabetes and Its Complications, 7, 57-62. https://doi.org/10.1016/1056-8727(93)90025-T

[24] Yavuzyilmaz, E., Yumak, O., Akdoganli, T., Yamalik, N., Ozer, N., Ersov, F, et al. (1996) The Alteration of Whole Saliva Constituents in Patients with Diabetes Mellitus. Australian Dental Journal, 41, 193-197. https://doi.org/10.1111/j.1834-7819.1996.tb04855.x

[25] Marder, M.Z., Abelson, D.C. and Mandel, I.D. (1975) Salivary Alterations in Diabetes Mellitus. Journal of Periodontology, 46, 567-569. https://doi.org/10.1902/jop.1975.46.9.567

[26] Streckfus, C.F., Marcus, S., Welsh, S., Brown, R.S., Cherry-Peppers, G. and Brown, R.H. (1994) Parotidfunction and Composition of Parotid Saliva among Elderly Edentulous African-American Diabetics. Journal of Oral Pathology \& Medicine, 23, 277-279. https://doi.org/10.1111/j.1600-0714.1994.tb00059.x

[27] Moore, P.A., Guggenheimer, J., Etzel, K.R., Weyant, R.J. and Orchard, T. (2001) Type 1 Diabetes Mellitus, Xerostomia and Salivay Flow Rates. Oral Surgery, Oral Medicine, Oral Pathology, Oral Radiology, and Endodontology, 92, 281-291. 
https://doi.org/10.1067/moe.2001.117815

[28] Prakash, C.K., Seraj, A.K. and Rajendra, K.C. (2014) Salivary Glucose Levels in Diabetic Patients: A Comparative Cross Sectional Study. International Journal of The rapeutic Applications, 18, 12-17. 